\title{
Cupá, ou cipó-babão, alimento de alguns índios amazônicos
}

\author{
Warwick E. Kerr \\ Darrell A. Posey \\ Wilson Wolter Filho \\ Instituto Nacional de Pesquisas \\ da Amaxônia, Manous
}

\section{INTRODUÇÃo}

Desde 1975, o INPA vem desenvolvendo pesquisas em plantas cultivadas peios índios, como por exemplo: cubiu, ariá, feijão-macuco, mandioca, macaxeira, batata-doce, amendoim, cará, taioba, fruteiras.

Numa palestra que um de nós (W. E. Kerr) fez em Rio Branco (Acre), um jovem ribeirãopretano (A. Petean, da FUNAI) informou que os ınaıos Gavioes (Parkateyê), localizados no Km 30 da Rodovia PA-70 (Marabá, Pará), plantam o cupá da mesma forma que a mandioca, por toletes (manivas). Também informou que os indios Kulina, do rio Envira, fazem intenso uso desta planta. Souza (1956) diz que os ínaıos Apinayé comem o cupá como verdura.

\section{ASPECTOS BOTÂNICOS}

Baker (1871) prefere chamar ao cupá de Vitis gongylodes Burch. ex Baker, dando Cissus como sinônimo. Descreve a planta assim:

...ramos glabros, sulcados, herbáceos, de $3-4 \mathrm{~mm}$ de espessura, sarmentosos, com muitas gavinhas. Estípulas deltóides, $12 \mathrm{~mm}$ de comprimento. Pecíolos grossos, herbáceos, glabros, $10-15 \mathrm{~cm}$ de comprimento. Folhas herbáceas, lisas na face superior, porém na parte inferior inconspicuamente acinzentado-purbérula; folíolos ternados, não imbricados, agudos; o folíolo terminal é deltóiderombóideo de $17,5-20 \mathrm{~cm}$ de comprimento e $15-17 \mathrm{~cm}$ de largura, profundamente 3- ou 5- lobado, os lobos eretos, agudos, os sinus inferiores profundos, a metade inferior do lobo deltóide; peciólulos de 14-20mm de comprimento. Nem as flores esverdeadas ou verde-amareladas (Burchell), nem a inflorescência e nem os frutos foram vistos.

Ocorren nas matas de S. José, Estado do Pará: Burchell 10072, e no Distrito de Maynas, Peru: Poeppig 2273.
Baker (I.c.) menciona duas espécies de Cissus: C. gongylodes e C. tricuspis como encontrados nas matas de São José, Pará.

O cupá selecionado pelos Kayapó tem $4 \mathrm{~cm}$ (e não $4 \mathrm{~mm}$ ) de diâmetro no seu ramo principal. O fino é chamado pelos Kayapó de "cupá-do-mato".

Pio Corrêa (1975) descreve brevemente Cissus gongylodes Burch. ex-Baker sob o nome vulgar "uva-do-mato". Completa a descrição de Baker, assinalando que as flores são agrupadas em corimbos umbeliformes, alvas ou levemente vinosas, cálice recoberto de pêlos grandulosos; os frutos são bagas, deprimidas, esféricas e roxo-negras, quando maduras, de 6 a $7 \mathrm{~mm}$ de diâmetro; indica seu habitat como sendo S. Paulo. Na mesma obra, Pio Corrêa (1926 e 1931) relata 2 espécies de Cissus: a) Cissus alata Jacq., encontrada em Minas Gerais e Rio de Janeiro (nome vulgar: "condurango", "chupão", "cipó-d'água", "mãe-boa"- cujas folhas têm uso medicinal caseiro, frutos comestíveis, e do cipó obtem-se seiva potável; b) Cissus sicyoides L.; de cujo fruto (baga preta) extrai-se uma tintura vermelha, que se torna azul. Era usada pelos índios Coroados, e outros, para tingirem seus panos. É encontrada em todo o Brasil com o nome de "anil-trepador", "tinta-de-índio", "uva-branca".

Elias (1968), ao fazer a revisão das Vitaceae do Panamá, informou que esta família tem 11 ou 12 gêneros e cerca de 700 espécies, dos quais apenas Vitis e Cissus são neotropicais. Dá a seguinte chave para distinguir Vitis de Cissus:

$1 \mathrm{~b}$ - Inflorescência em panícula bem desenvolvida; flores pentâmeras; pétalas fendidas no ápice que caem precocemente como 
um dedal (deáduo); folhas simples; medula castanha ....................... Vitis.

1b - Inflorescência cimosa; flores tetrâmeras; pétalas livres, que se expandem, caindo uma por uma; folhas simples ou trifoliadas; medula branca ................. Cissus.

Elias (o.c.) diz haverem 400 espécies de Cissus nos trópicos, porém, não informa quantas são neotropicais. A folha de Cissus parece a "era", um cipó da família Moraceae, usado para aderir em paredes; "Kissus" é "Era" em grego.

As espécies contidas no herbário do INPA são:

1 - Cissus erosa L.C. Rich. (Kubitzki 75-76) - Proc.: Baixo rio Negro, Paraná do Canta Galo. Idem... (Junk 156) - Proc.: Lago do Janauari, perto do Carreiro. Idem... (P.J.M. \& H. Maas 501) - Proc.: Manaus, à margem de estrada em mata secundária, perto do Parque 10.

2 - Cissus gongylodes Burch. ex Baker - Proc.: Pará, Belém. Idem... (Lisboa et al. 722) - Proc.: Mato Grosso, Aripuanã, Dardanelos, Iha dos Patos.

3 - Cissus sicyoides L. (P.J.M. \& H. Maas 355) - Proc.: Manaus, Rua Major Gabriel, à margem da estrada. Idem... (P.J.M. \& Maas 231) - Proc.: Cachoeirinha, margem da estrada.

O Museu Paraense Emílio Goeldi é mais completo e possui exsicatas de 8 espécies. As cinco que faltam no INPA são: $C$. haematanha, C. palmata, C. parker, C. rhombifolia e C. sulcicaulis.

\section{USO DO CUPÁ PELOS SERINGUEIROS}

Souza (1956) cita o cupá, ou cipó-babão (Cissus gongylodes Burch. ex Baker), como um agente coagulante do látex de Hevea usado por seringueiros do norte de Mato Grosso e em todo o médio e alto Tapajós, rio São Miguel e rio Juruena. Isso foi observado por $\mathrm{J}$. Murça Pires e George A. Black. Segundo eles, os seringueiros usavam o cupá quando, por efeito das chuvas, o látex se apresentava diluído, dificultandc, assim, a defumação em bolas. Sua adição ao látex, feita esmagando pe- quena porção em água, conferia a este o poder de "engrossar" o látex. O cupá, cortado, solta uma baba mucilaginosa. Produz cachos de flores pequenas, avermelhadas e frutos parecidos com a uva. É da família Vitaceae e é próximo ao gênero Vitis (ao qual pertence a uva). Souza demonstrou que o cupá contém ácido tartárico.

\section{USO DO CUPÁ PELOS ÍNDIOS}

Um de nós (D.A. Posey) coletou dados entre os indios Kayapó. Eles plantam as manivas verticalmente, enterrando $20 \mathrm{~cm}$ aproximadamente, e deixando outro tanto para fora, usualmente encostada ao tronco de uma árvore. Após brotar desenvolve-se na árvore até grandes alturas. Alqumas plantas estavam em plantações com mais de 40 anos. Cresce em solos pobres; requer luz, ou seja, não é cultivada na floresta mas em campos velhos, abertos. As manivas são comidas pelos Kayapó, :anto assadas (assam-nas por 15 a 30 minutos) como cozidas. Em ambos os casos retiram a casca e comem a medula. Também, fazem um beiju, amassando as medulas e produzindo uma massa. Essa massa pode ser seca ao sol para uso posterior ou consumida pura ou em mistura com castanhas ou com carne (de caça ou peixe); neste caso embrulham em folha de bananeira e assam. Também, secam e transformam em farinha, que usam como farinha fina e fazem um tipo de pão.

$\mathrm{Na}$ obra de Nimuendaju $(1956: 69)$ lemos:

A antiga e típica planta de cultivo dos Timbira, Kayapó e Xerente, a kupá (Cissus sp.), hoje só excepcionalmente é cultivada.

Arnaud (1975:27) informa em sua obra sobre os Gaviōes de Oeste:

Cultivo principalmente da batata doce (Ipomoea batatas); cará (Dioscorea $\mathrm{sp}$ )... inhame (Alocasia indica); taioba (Colocasia antiquorum) e kupá (Cissus sp.) provavelmente a mais importante espécie tradicionalmente cultivada pelos Timbira.

\section{DADOS AGRONÔMICOS}

Um de nós (Darrel A. Posey) que estava estudando os conhecimentos entomológicos dos Kayapó, coletou e enviou ao INPA algumas 
manivas. Da primeira vez remeteu 10 manivas por intermédio do Museu Paraense Emílio Goeldi. Por uma deficiência de informação, a caixa com as manivas permaneceu mais de um mês em Belém. Enı 06-05-78 foram plantadas, duas em Belém e 8 em Manaus. As duas de Belém brotaram e, das 8 de Manaus, brotaram seis (apesar das condições anômalas, o pegamenio foi de $80 \%$ ).

Em 06-08-78 foram coletadas mais 14 manivas de cupá que chegaram a Manaus em 21-08-78 e 11 foram plantadas no dia seguinte, uma no dia 01-09-78 e duas foram reservadas para análise química.

As 6 plantas que obtivemos, da primeira leva, e plantamos em Manaus, aos 4 meses, apresentavam-se com uma média de $58 \mathrm{~cm}$ ( $s=74$ isto é, apresentavam plantas desde 2 até $200 \mathrm{~cm}$ de altura), crescimento esse conseguido durante o fim do inverno e 3 durante o verão (04-05 a 23-08-78), o que, junto com as adversidades do transporte, explicam a grande variabilidade observada. $O$ número médio de folhas foi, após 4 meses, de $9(s=8)$. As plantas à meia sombra desenvolveram muito meIhor que as a pleno sol (algumas destas morreram).

As manivas plantadas em Belém desenvolveram-se melhor.

Comemos um pedaço de cupá e todos achamos o seu gosto muito parecido ao da macacheira.

\section{Dados QUímicos}

As análises químicas que fizemos (W. Wolter Filho) a partir de um único exemplar, revelaram o seguinte:

A proporção entre a casca e o âmago (que é a parte comestivel), em 100 gramas de cupá, foi: $35 \%$ de casca e $65 \%$ de âmago.

0 teor de umidade no âmago é $73 \%$.

Usando a técnica de cromatografia em fase gasosa, verificamos que não possui ácido oxálico, porém contém ácido tartárico

Por cromatografia líquida a alta pressão constatamos também que não possui as vitaminas $A, B_{1}, B_{2}, B_{6}, C, D_{2}, D_{3}$ e E. O teste qua- litativo (reação de Carr-Price) deu negatividade para a vitamina $A$ (técnica descrita por Strohecker, 1965).

Um líquido oleoso extraído do cupá é, em $70 \%$, constituído de material insaponificável (esteróis).

Numa amostra cozida, encontrou-se no âmago: $77,56 \%$ de água; $1,2 \%$ de proteína; $1,0 \%$ de gordura; $1,4 \%$ de cinzas; $18,84 \%$ de carbohidratos; 89,2 cal. de energia.

\section{AGRADECIMENTOS}

Agradecemos aos índios Kayapó de Gorotire (rio Xingu), por nos darem o material que selecionaram durante centenas de anos; ao $\mathrm{Dr}$. William A. Rodrigues por nos indicar biblıografia e corrigir alguns erros botânicos no nosso primeiro manuscrito; ao $\mathrm{Sr}$. Jaime Paiva e $\mathrm{Dr}$. Roger Shrimpton pela análise de proteína e carbohidratos. A Dra. Marlene F. Silva pelas traduçōes do latim e informaçōes sobre o herbário.

\section{SUMMARY}

INPA is developing studies concerning the agricultural plants of the Brazilian Indians. A collection was made among the Kayapo Indians of the Cupa vine (Cissus gongylodes Burch. ex Baker, Vitaceae). This note provides botanical information on this plant, its uses by the seringueiros (rubber collectors) and by the indians, and agronomical and chemical data.

\section{BIBLIOGRAFIA CITADA}

ARNAUD, EXPEDITO

1975 - Os indios Gaviōes de Oeste. Pacificaçẩo e integração. Publicaçōes avulsas do Museu Goeldi, (28) : 1-86.

BAKER, J.G.

1871 - Connaraceae, Ampelideae. In: Martius - Flor. Bras. fasc. 15, v. 14(2) : 173-216, tab. 41-52.

ELIAS, Tномаs $\mathrm{S}$.

1968 - Family 112. Vitaceae. In: Flora of Panama - Woodson Jr., R.E. \& Schery, R.W. Part VI. Ann. Missouri Bot. Gard., 55(2) : 81-92. 
NIMUENDAJU, CURT

1956 - Os Apinayé. Bol. do Mus. Emílio Goeldi, $12: 1-150$.

Pio CORREA, M.

1926 - Dicionário de plantas úteis do Brasil e das exóticas cultivadas. Rio de Janeiro, Imp. Nac., p. 130.

1931 - Dicionário de plantas úteis do Brasil e das exóticas cultivadas. Rio de Janeiro, Imp. Nac., v. 2, p. 255.

1975 - Dicionário de plantas úteis do Brasil e das exóticas cultivadas. Rio de Ja- neiro, Instituto Bras. Des. Florestal v. 6, p. 369 .

Souza, Hillkias BERNARdo dE

1956 - O cipó-babão (Cissus gongylodes Baker). Um agente coagulante do látex de Hevea. Bol. Técnico do Instituto Agronômico do Norte, (31):163-186.

STROHECKER, ROLF

1965 - Vitamin assay. Verlag Chemie Darmstadt, p. 353.

(Aceito para publicação em 14/09/78) 